\title{
Correction to: Fatigue fracture characterization by cyclic material forces in viscoelastic solids at small strain
}

\author{
Jad Khodor • Kaan Özenç • Aurel Qinami • \\ Guoyu Lin $\cdot$ Michael Kaliske (1)
}

Published online: 1 March 2022

(C) Springer Nature B.V. 2022

Correction to: International Journal of Fracture https://doi.org/10.1007/s10704-021-00607-x

Due to an unfortunate turn of events numerous equations contained ambiguous mistakes. Because of that fact the article has been updated with respect to the equations.

Publisher's Note Springer Nature remains neutral with regard to jurisdictional claims in published maps and institutional affiliations.

The original article can be found online at https:// doi.org/10.1007/s10704-021-00607-x.

J. Khodor · A. Qinami · M. Kaliske ( $\square)$

Institute for Structural Analysis, Technische Universität

Dresden, 01062 Dresden, Germany

e-mail: michael.kaliske@tu-dresden.de

K. Özenç · G. Lin

ANSYS Inc., Canonsburg, PA 15317, USA 